\title{
Tradisi Minum Kopi Sebagai Rangkaian Acara Pernikahan di Kenagarian Kapelgam Kecamatan Bayang Pesisir Selatan
}

\author{
Mesy Maisara, Susi Fitria Dewi \\ Prodi Pendidikan Pancasila dan Kewarganegaraan \\ FIS Universitas Negeri Padang \\ E-mail: susifd@yahoo.com
}

\section{ABSTRAK}

Tradisi minum kopi merupakan salah satu rangkaian acara pernikahan yang harus dilalui oleh pengantin di Kenagarian Kapelgam, Kecamatan Bayang, Kabupaten Pesisir Selatan. Namun, tradisi ini semakin lama semakin hilang di dalam masyarakat. Penelitian ini bertujuan untuk mendeskripsikan makna yang terkandung dalam tradisi minum kopi dan mengidentifikasi faktor-faktor penyebab kurangnya partisipasi masyarakat dalam tradisi tersebut. Penelitian ini menggunakan pendekatan deskriptif kualitatif dengan dua sumber data yakni mewawancarai 12 orang informan selama 14 hari dan juga observasi pada saat pelaksanaan tradisi minum kopi. Hasil penelitian ini menunjukkan bahwa makna yang terkandung dalam tradisi minum kopi adalah memaksimalkan peranan laki-laki seperti niniak mamak dalam merumuskan kebutuhan perhelatan pada saat pesta pernikahan. Sementara itu, secara tidak langsung ada manfaat sosial yang bisa dirasakan oleh tuan rumah yaitu mendapatkan bantuan materi dari kerabat. Tradisi minum kopi juga dapat melestarikan budaya yang sudah ada di Kenagarian Kapelgam. Penelitian ini menemukan faktor-faktor penyebab kurangnya partisipasi kaum laki-laki dalam tradisi minum kopi adalah karena tidak adanya sanksi dari pemuka masyarakat serta pengaruh dari budaya luar. Kaum laki-laki semakin tidak peduli dengan pelaksanaan makan bersama yang dilakukan sampai tengah malam. Hal ini menjadikan tradisi minum kopi semakin luntur di tengah masyarakat.

Kata Kunci: tradisi minum kopi, Minangkabau, adat, pesta pernikahan ABSTRACT

The tradition of drinking coffee is one of a series of wedding events that must be passed by the bride and groom in the Kenagarian Kapelgam, Bayang District, Pesisir Selatan Regency. However, this tradition is getting lost in society over time. This study aims to describe the meaning of coffee drinking tradition and identify the factors that cause the lack of community participation. This study used a qualitative descriptive approach with two data sources; interviewing 12 informants for 14 days and also observing the implementation of the coffee drinking tradition. The results of this study indicate that there are three meanings contained in the tradition of drinking coffee, including maximizing the role of men such as niniak mamak in formulating event needs at the weddings. Meanwhile, indirectly there are social benefits that can be felt by the host and can preserve the existing 
culture. This study found that the factors causing the lack of men's participation in the coffee drinking tradition are due to the absence of sanctions from community leaders and influence from outside cultures. Men also care less of this tradition and the implementation of eating together until midnight makes this tradition fade in society.

Keywords: drinking coffee tradition, minangkabau, culture, wedding ceremony

\section{PENDAHULUAN}

Masyarakat adat di Indonesia memiliki tradisi yang berbeda-beda di setiap daerah. Perbedaan tersebut terlihat dari beragamnya tradisi yang ada di Indonesia. Dalam arti sempit tradisi adalah kumpulan benda dan gagasan yang diberi makna khusus yang berasal dari masa lalu. Tradisi adalah adat kebiasaan turun temurun (dari nenek moyang) yang masih dijalankan dalam masyarakat, serta penilaian atau anggapan bahwa caracara yang telah ada merupakan yang paling baik dan benar (Aliya, 2008). Tradisi tersebut dapat mengalami perubahan dari masa ke masa. Perubahan kuantitatifnya dapat dilihat dari jumlah warga yang melaksanakan tradisi tersebut. Sedangkan perubahan kualitatifnya dapat dilihat pada perubahan gagasan, simbol, dan nilai-nilai tertentu yang ditambahkan atau dikurangi dalam tradisi. Perubahan tersebut terjadi ketika masyarakat memberikan perhatian khusus pada satu tradisi dan mengabaikan tradisi yang lain (Sztompka, 2014). Tradisi bukanlah sesuatu yang statis, perubahan dapat dilihat dan didokumentasikan pada produk budaya, praktek dan nilai (Varnum, 2017).
Tradisi sinamot misalnya, berguna sebagai sarana pengikat antara kelompok kekerabatan dan memperkuat integrasi social (Manik, 2011). Tradisi ini dapat kita temukan pada upacara perkawinan suku Batak di Surabaya. Di Purworejo Jawa Tengah juga terdapat tradisi pasang tuwuhan yang dilaksanakan pada upacara pernikahan sebagai bentuk rasa syukur serta untuk menyambut kehadiran tamu yang datang. Lain halnya pada masyarakat di Jawa Timur yang melaksanakan tradisi brobosan pada upacara kematian yang dilakukan dengan cara berjalan di bawah keranda mayat yang sedang di angkat tinggi.

Pola pikir masyarakat masih dipengaruhi oleh tradisi terutama terkait dengan nilai kebersamaan dan nilai komunal (kelompok). Nilai-nilai tersebut terlihat dari beberapa wilayah di Indonesia yang memiliki tradisi dan adat yang masih kental. Salah satu tradisinya adalah tradisi minum bersama yang dilaksanakan bertujuan untuk mempererat hubungan kekerabatan. Beberapa praktik tradisi meminum minuman tradisional dapat kita temukan di berbagai suku di Indonesia. Seperti yang terlihat pada masyarakat Jambi 
Journal of Civic Education (ISSN: 2622-237X)

Volume 4 No. 12021

yang melaksanakan tradisi minum daun kawo untuk mengikat hubungan kekerabatan (Bahar, 2017). Hal serupa juga ditemukan pada masyarakat desa Tegalrejo Kecamatan Merakurak Tuban yang mengadakan tradisi minum tuak sebagai minuman penyambung tali persaudaraan dan mempererat hubungan kekerabatan (Fatmawati, 2018).

Di Sumatera Barat juga terdapat tradisi minum teh yang disebut dengan kawa daun yang dilakukan oleh masyarakat Batusangkar dan Bukittinggi. Pada awalnya tradisi minum kawa daun dilakukan oleh para pekerja pribumi di dangau di tepi sawah atau ladang ketika mereka beristirahat melepas lelah setelah bekerja. Adapun tradisi itu dinamakan dengan tradisi pai maanta kawa yaitu mengantarkan makanan dan minuman untuk pekerja yang sedang bekerja di sawah atau di ladang (Lestari dkk, 2019).

Sementara dalam penelitian ini, penulis ingin melihat tradisi minum kopi yang dilaksanakan di Kenagarian Kapelgam, Kecamatan Bayang, Kabupaten Pesisir Selatan. Tradisi ini merupakan salah satu rangkaian dalam acara pernikahan. Tradisi ini dilakukan seminggu sebelum acara pernikahan dimulai yang bertujuan untuk memberi tahu kepada niniak mamak, urang sumando, keluarga dan masyarakat setempat bahwa akan diadakan acara pernikahan.

Seiring perkembangan zaman, terdapat pergeseran dalam tradisi minum kopi. Beberapa orang dari kaum laki-laki mulai berkurang partisipasinya. Sehingga dalam artikel ini peneliti tertarik untuk melihat faktor apa yang menyebabkan kurangnya partisipasi masyarakat dalam mengikuti tradisi minum kopi. Pertanyaan lain yang ingin dijawab adalah makna apa yang terkandung dalam tradisi minum kopi sehingga penting untuk dilestarikan sebagai rangkaian dalam acara pernikahan.

\section{METODE PENELITIAN}

Penelitian ini bersifat deskriptif dengan menggunakan pendekatan kualitatif. Penelitian kualitatif bertujuan untuk memahami suatu fenomena dalam konteks sosial (Herdiansyah, 2010:9). Jenis data yang digunakan adalah data primer dan sekunder, dengan teknik pengumpulan data melalui observasi dan wawancara. Wawancara dilakukan kepada beberapa orang tokoh adat dan tokoh masyarakat di Kenagarian Kapelgam. Teknik pengujian keabsahan data dilakukan dengan teknik triangulasi sumber data serta analisis teknik reduksi dan verifikasi data.

Triangulasi merupakan metode sintesa data terhadap kebenarannya menggunakan metode pengumpulan data yang lain atau berbagai paradigma triangulasi (Bachri, 2010). Reduksi data adalah proses pemilihan, pemusatan perhatian pada penyederhanaan, pengabstrakan dan transformasi data kasar yang muncul dari catatan-catatan tertulis di lapangan (Agusta, 2003).

\section{HASIL DAN PEMBAHASAN}

Berdasarkan penelitian yang telah dilakukan di Kapelgam Kecamatan Bayang Kabupaten Pesisir 
Selatan dapat dijelaskan bahwa makna yang terkandung dalam tradisi minum kopi adalah dapat menjalin dan mengeratkan hubungan silaturahmi. Selain itu tradisi ini dapat membantu secara materi penyelenggara acara pernikahan. Partisipasi masyarakat dalam acara tradisi minum kopi ini cukup baik namun bisa dikatakan belum sepenuhnya sempurna.

Di dalam tradisi minum kopi terdapat tiga makna yang ditemukan dalam penelitian ini. Pertama, memaksimalkan peranan kaum lakilaki khususnya niniak mamak dalam mempersiapkan acara pernikahan anak kemenakan. Dalam pelaksanaan tradisi minum kopi, niniak mamak diundang untuk mendapatkan informasi kapan anak kemenakannya akan melangsungkan pesta pernikahan. Biasanya upacara pernikahan ditetapkan satu sampai dua minggu setelah tradisi minum kopi dilaksanakan. Mengingat waktu yang sudah dekat dengan hari $\mathrm{H}$, maka melalui tradisi minum kopi inilah kaum laki-laki diajak berpartisipasi baik moril maupun materil guna mensukseskan upacara pernikahan. Setiap laki-laki yang datang, biasanya secara sukarela hadir dan memberikan sedikit sumbangan uang. Namun makna terkuat dari tradisi ini adalah memaksimalkan peranan kaum lakilaki untuk mensukseskan pesta pernikahan. Bagi kaum laki-laki yang hadir, mereka akan merasa dihargai karena memiliki peran dalam kegiatan sosial kemasyarakatan.

Kedua, dalam tradisi minum kopi terdapat manfaat sosial bagi tuan rumah yang mengadakan tradisi minum kopi. Makna ini dapat dirasakan oleh tuan rumah dan juga kaum laki-laki yang datang dalam tradisi minum kopi. Bantuan sosial yang diberikan oleh tamu undangan pada tradisi minum kopi sangat membantu meringankan biaya pernikahan yang akan diadakan oleh tuan rumah.

Ketiga, mempererat silaturahmi antar masyarakat khususnya kaum laki-laki di Nagari. Mereka bisa berkumpul dan saling memberi informasi mengenai keadaan Nagari. Pada saat minum kopi, kaum laki-laki akan membahas banyak hal, mulai dari urusan pribadi, keluarga, masyarakat bahkan negara. Moment tradisi minum kopi bahkan dapat dijadikan ajang memecahkan masalah yang terdapat dalam Nagari.

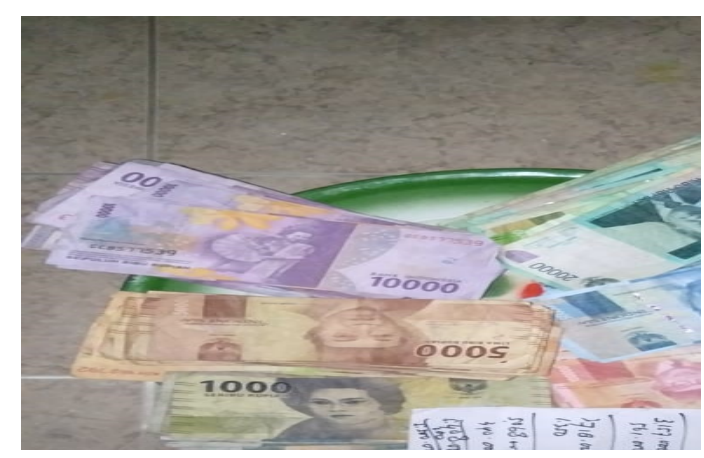

Gambar 1. Uang yang tekumpul saat tradisi minum kopi

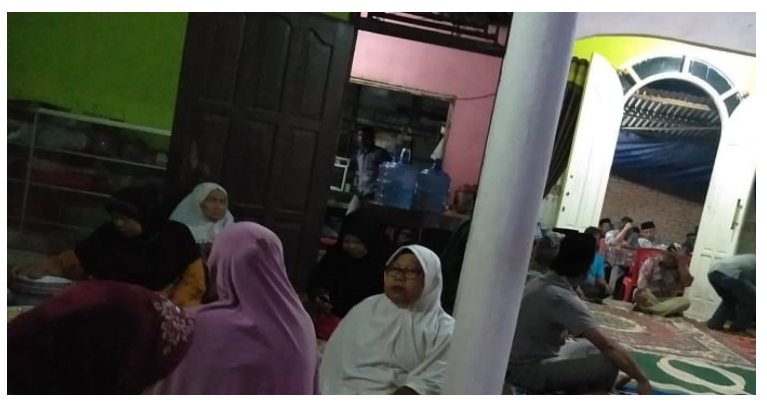

Gambar 2. Suasana silaturahmi pada saat acara minum kopi 
Journal of Civic Education (ISSN: 2622-237X)

Volume 4 No. 12021

Penelitian ini menemukan lima faktor penyebab kurangnya partisipasi masyakarat dalam tradisi minum kopi. Pertama, kurangnya pengetahuan tentang pentingnya makna minum kopi dari kaum lakilaki. Wawancara yang peneliti lakukan kepada bapak Muchtar pada tanggal 16 Juni 2020 mengakui bahwa partisipasi masyarakat pada saat sekarang ini masih rendah dalam mengikuti pelaksanakan tradisi minum kopi. Bapak Azhar Noeri Dt. Rajo Nan Putiah, sebagai tokoh adat juga mengatakan bahwa perubahan yang diakibatkan oleh budaya luar yang masuk ke Kenagarian Kapelgam telah mengakibatkan masyarakat tidak lagi peduli dengan adatnya sendiri.

Kemajuan zaman telah membawa pergeseran di segala aspek dalam kehidupan bermasyarakat. Pergeseran tersebut semakin terlihat dari hilangnya kebudayaan lama yang seharusnya dapat dilestarikan. Bapak Emrizal selaku tokoh masyarakat mengatakan bahwa hal ini merupakan suatu bentuk konsekuensi dari dinamika kebudayaan karena adanya proses akulturasi, perubahan pola pikir dan pola hidup masyarakat. Tidak antusiasnya kaum laki-laki dalam melaksanakan tradisi minum kopi karena mereka merasa tidak mau disibukkan dengan tradisi lagi. Pada siang hari mereka sudah lelah bekerja dan terkadang ada yang lembur sampai malam hari. Sehingga kaum laki-laki memanfaatkan waktu malam untuk beristirahat.

Kedua, tidak adanya sanksi dari pemuka masyarakat terutama sanksi social telah membuat kaum laki-laki tidak segan atau merasa bersalah apabila tidak mengikuti tradisi minum kopi. Apabila dalam tradisi minum kopi terdapat sanksi sosial bagi yang tidak melaksanakannya, maka mungkin akan membuat tradisi ini terus terjaga kelestariannya. Ketiga, pengaruh dari budaya luar yang menyebabkan terjadinya kemerosotan adat istiadat yang ada pada masyarakat Minangkabau. Hal ini juga berdampak buruk terhadap tradisi minum kopi karena masyarakat tidak mau lagi dilibatkan dalam tradisi adat. Dahulunya setelah tradisi minum kopi selesai dilanjutkan dengan makan bersama, namun saat sekarang ini sudah tidak dilaksanakan lagi. Hal ini merupakan salah satu bentuk pergeseran tradisi adat istiadat yang disebabkan oleh masyarakat tidak mau berlama-lama dalam mengikuti acara tradisi minum kopi. Sementara itu, tuan rumah juga tidak mau direpotkan karena yang menghidangkan makanan adalah urang sumando, sehingga memerlukan pengaturan lebih lanjut.

Keempat, pelaksanaan acara minum kopi sudah dimulai menjelang tengah malam. Dahulunya waktu pelaksanaan tradisi minum kopi ini dimulai setelah sholat magrib, namun tidak pada saat sekarang ini yang mengalami perubahan dimana waktu pelaksanaan dimulai sesudah sholat isya dan tidak jarang dimulai sudah lewat dari pukul 21:00 WIB. Waktu pelaksanaan yang terlalu lama membuat tradisi minum kopi sudah tidak diminati lagi bagi sebagian masyarakat di Kenagarian Kapelgam.

Gambar 3. Sebagian tamu yang sedang menunggu undangan lain yang belum datang 


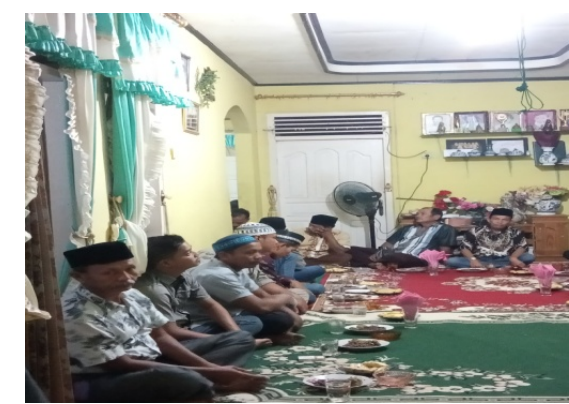

KESIMPULAN

Tradisi minum kopi di Kenagarian Kapelgam Pesisir Selatan masih tetap dilaksanakan walaupun terjadi penyesuaian terhadap tradisi tersebut. Makna yang terkandung dalam tradisi minum kopi bisa dirasakan oleh tuan rumah dan juga kaum laki-laki yang diundang. Kaum laki-laki dapat memaksimalkan perannya di dalam masyarakat dengan saling bersilaturahmi. Sehingga tradisi minum kopi ini memiliki dampak sosial di tengah masyarakat. Namun, partisipasi kaum laki-laki pada saat sekarang ini semakin berkurang, hal ini dilatarbelakangi oleh beberapa factor; kurangnya kepedulian kaum laki-laki, tidak adanya sanksi sosial, adanya pengaruh dari budaya luar, kebiasaan masyarakat yang tidak lagi melaksanakan makan bersama serta pelaksanaan tradisi minum kopi yang dimulai menjelang tengah malam. Semua factor ini berpengaruh terhadap memudarnya tradisi minum kopi di Kenagarian Kapelgam.

\section{DAFTAR PUSTAKA}

Agusta, I. (2003). Teknik Pengumpulan dan Analisis Data Kualitatif. Pusat Penelitian Sosial
Ekonomi. Litbang Pertanian, Bogor, 27.

Aliya, Qonita. (2008). Kamus Bahasa Indonesia Untuk Pendidikan Dasar, PT. Indahjaya Adipratama,tk.

Bachri, B. S. (2010). Meyakinkan validitas data melalui triangulasi pada penelitian kualitatif. Jurnal Teknologi Pendidikan, 10(1), 46-62.

Bahar, Mahdi dkk. 2017. Fenomenama Tradisi Minum Daun Kawo Di Desa Ujung Pasir. Jurnal Titian, Vol. 1, No.2

Fatmawati Rohmana. 2018. Tradisi Minum Tuak Di Desa Tegal Rejo Kecamatan Merakurak Kabupaten Tuban. Skripsi. Surabaya: Fakultas Ilmu Sosial Dan Politik UIN Sunan Ampel.

Herdiansyah, H. (2010). Metodologi penelitian kualitatif untuk ilmuilmu sosial. Jakarta: Salemba Humanika, 8.

Lestari, N. S., \& Natalina, H. D. (2019). Kawa Daun, Kopi yang Bukan Berasal dari Biji Kopi. Jurnal Sains Terapan Pariwisata, 4(2), 262-276.

Manik, Septiani helga. 2011. Makna Dan Fungsi Tradisi Dalam Adat Perkawinan Suku Bangsa Batak Toba di Perantauan Surabaya. Jurnal Biokultur, Vol. 1, No. 2

Sztompka, P. (2014). Agency and Structure (RLE Social Theory): Reorienting Social Theory. Routledge.

Varnum, M. E. W., \& Grossmann, I. (2017). Cultural Change: The How and the Why. Perspectives on Psychological Science, 12(6), 956-972. 